\title{
Determinants of Cohesion in Smallholder Farmer Groups in Uganda
}

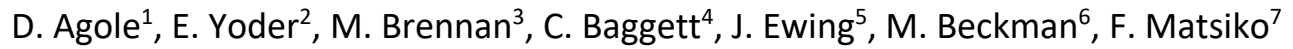

\section{Abstract}

Cohesion is a fundamental determinant of performance in farmer groups in which collective action is pursued for the benefit of the members. The study examined the influence of individual members' objectives, participation culture, group rewards, structure of tasks and perceived equity on cohesion of farmer groups that may promote access to agricultural extension services. Quantitative data were collected via questionnaire from 180 members of 19 farmer groups using a multi-stage process that combined purposive and random sampling. Qualitative data were gathered from 20 key informants in oral interviews and three focus group discussions. Regression analysis indicated that there were statistically significant negative relationships between individual members' objectives, structure of the tasks, group reward system and cohesion of farmer groups. In contrast, perceived equity had a marginally significant positive relationship with cohesion in farmer groups. We recommend that, for sustainability of group cohesion, group facilitators work with the farmer groups to enhance alignment of group and NAADS (National Agricultural Advisory Services) institutions and performance indicators. A group dynamics perspective to understanding farmer group cohesion should be a helpful organizing principle.

\section{Keywords}

NAADS, advisory services, community interactions

1. David Agole, Faculty of Vocational Studies, Kyambogo University, P.O Box 1 Kyambogo, Uganda, agoledavid@yahoo.com, https://orcid.org/0000-0002-1297-983X

2. Edgar Yoder, Professor, The Pennsylvania State University, 002 Ferguson Building, University Park, PA 16802, epy@psu.edu, https://orcid.org/0000-0002-6927-9252

3. Mark A. Brennan, Professor, The Pennsylvania State University, 204 Ferguson Building, University Park, PA 16802, unescochair@psu.edu, https://orcid.org/0000-0001-8434-3948

4. Connie Baggett, Associate Professor, The Pennsylvania State University, 207 Ferguson Building, University Park, PA 16802, bbc@psu.edu, https://orcid.org/0000-0001-5597-3094

5. John Ewing, Associate Professor, The Pennsylvania State University, 215 Ferguson Building, University Park, PA 16802, jce122@psu.edu, https://orcid.org/0000-0002-9189-1106

6. Matthew Beckman, Assistant Research Professor, The Pennsylvania State University, 323F Thomas Building, University Park, PA 16802, , mdb268@psu.edu, https://orcid.org/0000-0002-6747-3289

7. Frank Biryabaho Matsiko, Lecturer, Makerere University, P.O. Box 7062, Kampala, Uganda, fbmatsiko@gmail.com, https://orcid.org/0000-0001-7363-2584 


\section{Introduction and Problem Statement}

Over $80 \%$ of Uganda's agricultural sector is dominated by smallholder farmers producing on less than two acres of land, with extremely low yields mostly to meet household food needs and in case of surplus it is sold. This is because most rural dwellers, where smallholder farmers are, live in the poverty level below U.S $\$ 1.90$. Given then a relatively high 5000 to 1 ratio of smallholder farmers per agricultural extension worker, most farmers are not reached by extension services, thus their production capacities remain low. To transform smallholder farmers that operate at a subsistence level into commercial farmers two initiatives were implemented (The Plan for Modernization of Agriculture and National Development Plan Three and Uganda's Vision 2040) with the intent of transforming the country into a middle-income economy.

Uganda farmers are currently organized in groups to easily access extension services and other capacity building interventions. Farmer groups are important avenues through which farmers access market and credit information as well as important agricultural information and technologies. Farmer groups also represent important avenues for mobilizing farmers around common objectives, especially those relating to service delivery and policy formulation in support of agricultural development (Adong et al., 2012; Salifu et al., 2010). In Uganda, the use of smallholder farmer groups remains central to the agricultural transformation process envisioned in the five-year Agriculture Sector Development Strategy and Investment Plan (DSIP) (2015 - 2020). The DSIP includes four pillars: i) enhancing production and productivity; ii) improving market access and value addition; iii) providing an enabling environment for the agricultural sector; and iv) strengthening of agricultural sector institutions (Ministry of Agriculture Animal Industry and Fisheries -MAAIF, 2010). Under Pillar One and Pillar Two, the existing farmer groups are envisioned to play a key role in improving produce marketing, increasing access to financing and value addition (MAAIF, 2010).

The National Agricultural Advisory Services (NAADS), a semi-autonomous body created by a 2001 Act of Parliament of Uganda, is charged with privately delivering publicly funded agricultural extension services to smallholder farmer groups. Since its inception in 2001, NAADS has been promoting farmer groups as nuclear organizations for this service delivery. The farmer group approach primary goal aims to improve both the efficiency of reaching many smallholder farmers and the effectiveness of promoting farmer ownership of extension services, especially when such initiatives target smallholder, resource-poor farmers (Mangheni, 2007). The farmer groups thus become centers for recruitment of farmers, selection of food security enterprises and distribution of multiple planting and stocking materials.

There is limited understanding of the drivers/facilitators of cohesion in farmer groups(Bukenya, 2010). This study examines the individual member's attributes and how participation context influences group cohesion in smallholder farmer groups in Uganda. It broadens the discussion by expanding the content to include group dynamics and the attendant group processes. 


\section{Theoretical and Conceptual Framework}

The study on which this research is based was informed by an integration of community interactional theory (Wilkinson, 1991) and social exchange theory (Stolte et al., 2001). The interactional theory helps one to gain insights into the influence of interactions among individual group members on cohesion of farmer groups. The theory postulates that a community is comprised of social fields, which allow people to connect and interact with one another to form community fields (Pigg, 1999; Wilkinson, 1991). From this perspective, interaction of community members through the social fields allows individuals to access community resources and information. It is also an enabler and motivator for people to join farmer groups in the hope of attaining benefits that accrue to group membership. Therefore, the strength or weakness of the social fields formed among individual group members is critical for accessing resources dispensed by the group. Proponents of the theory argue that community fields link community members and, if strong, may influence group inclusion and cohesion.

Social exchange theory for its part posits that society involves interactions among individuals that are based on rewards and punishments (Cropanzano \& Mitchell, 2005). Proponents of the theory (Lin et al., 2005) argue that individuals join groups on the basis of calculations that indicate that doing so enables these individuals to meet personal needs and pursue those interests alongside the collective goals of groups. Theory also recognizes that individual interests are constrained by the collective group interests and processes such as norms and regulations (Stolte et al., 2001). Accordingly, individuals cannot invest their efforts and resources in group activities and doggedly pursue rents accruing to this investment without paying attention to potential sanctions the group may impose in the event of errant behavior.

The conceptual framework is derived from interactional and social exchange theories. Both interactional and social exchange theories consider community contextual factors: the community culture and individual member personal attributes that largely emanate from the community; and group processes and dynamics such as rules and regulations on allocation and tasks and rewards, and leadership structures represent the social exchange theory. An interaction between community and individual member contextual factors and the supportive/restrictive level at which an individual member meets his/her personal interests tend to influence the level of cohesion in a group representing interactional theory.

\section{Purpose}

The primary purpose of this study was to examine factors that influence group cohesion in farmer groups that access agricultural advisory services from the National Agricultural Advisory Services in Uganda. More specifically, the study assesses the influence of individual members' objectives, participation culture of members, structure of group tasks, reward system, and perceived equity on cohesion of farmer groups. 


\section{Methods}

This study used a cross-sectional design to obtain the views of 200 participants selected from Kyere, Olio, and Arapai sub-counties of Soroti district. A key criterion in selecting the study district and sub-counties was to study entities whose group dynamics would ordinarily be expected to have matured. Thus, the study examined 19 farmer groups that had been continuously operational in the study district between 2001 through 2011.

The participant selection process adopted a multi-stage sampling strategy that combined stratified random and purposive sampling techniques. Based on the decentralized operational structure followed by NAADS, a two-stage stratified sampling with the sub county as the first stage and the village as the second stage was used for area sampling. At the village level, the number of groups was selected proportionately basing on the number of farmer groups in a sub county. The sampling selection of members in a group was by proportional allocation with proportionately more respondents selected from farmer groups with more members.

The group chairpersons as recognized by the group members (one chairperson in each selected group) were purposively selected because they were assumed to be knowledgeable about group activities and facilities within the locality. The smallholder farmers were stratified into active group members and those that had quit their groups. Thirty participants were then randomly sampled for each stratum making a total of 60 participants for each sub-county and a district total of 180 participants. In addition, three sub-county NAADS coordinators (SNCs), 12 former farmer group members and five opinion leaders were purposively selected making a total of 20 key informants. These key informants were selected for their knowledge of the context in which the farmer groups operate, and the processes used to engage the membership.

While work continues with these farmer groups, specific data for this current study were gathered in October 2011. This date was approximately four to nine years after the initial group contact with the NAADS program. Data collection was primarily done using paper questionnaire guided face-to-face interviews and focus group discussions. The questionnaire was reviewed for content validity by a panel of experts comprised of agricultural extension experts that constituted dissertation committee and NAADS agricultural advisors. In addition, the interviewer-administered paper survey was pilot tested by administering it to 20 members of farmer groups not included in the final study.

The survey collected data regarding group member individual objectives, structure of tasks, perceived equity, and group cohesion. Under individual objectives, the investigator asked questions such as what personal needs were expected to be met upon joining the group and rating those needs. Structure of group tasks addressed questions such as the tasks you were involved in, rating your level of involvement, and rating the level of your competence regarding the tasks. Items regarding reward focused on benefits obtained from other group members and how other group members benefited from their individual participation in the group. Other 
items in the reward section focused on the individual member's contribution to overall group operation and cohesion and future intent of the individual to participate in the group. In the perceived equity section items focused on satisfaction with criteria used in allocating group tasks, satisfaction with allocation of group rewards and satisfaction with the way group members are treated. Group cohesion items focused on individual member's pride in belonging to the group and member turnover in the group.

Key quantitative variables were analyzed using basic descriptive statistics generated with the Statistical Package for Social Scientists (SPSS) version 19. Cronbach's alpha was used to assess the internal consistency of summated Likert values associated with latent factors identified by the exploratory factor analysis. All Cronbach alpha values were greater than 0.7 (Urdan, 2010).

Factor analysis was completed to extract correlation coefficient matrix of factors that highly correlated $(r<0.9)$, that is, factors that greatly contribute to cohesion and performance subsequently. Factor extraction was done to generate eigenvalues associated with each factor before ( 37 factors identified from the data set) and after ( 7 factors) extraction, as well as after rotation. The 7 factors were identified by attaching percentages to eigenvalues and accounted for $73.3 \%$ of the total variance. The rotated component matrix was extracted and factor loadings less than 0.4 were excluded, and factors were sorted by size. Questions that loaded onto the same factor were identified and common themes were generated. Furthermore, correlation coefficient analysis was used to determine the relationship between the various motivation factors. Linear regression analysis was used to determine the relative influence of different factors on group cohesion.

\section{Findings}

\section{Individual Members Objective}

Arguably, a key force that tends to draw group members together is a commonality of individual members' objectives. We, accordingly, were concerned with examining the major benefits that drew individuals to farmer groups in Uganda. Table 1 provides the descriptive results on needs that farmers expected to meet upon joining their various groups and the perceived extent to which those needs had been met. 
Table 1

Reasons Member Joined Groups

\begin{tabular}{llllll}
\hline Need & N & M & (SD) & \% with Expectation & Needs Met \% \\
& & & & & \\
\hline Access knowledge and skills & 150 & 4.21 & $(1.28)$ & 15.8 & 51.2 \\
Improved seed & 138 & 4.06 & $(1.37)$ & 14.6 & 19.8 \\
Improved animal breeds & 127 & 4.02 & $(1.33)$ & 13.4 & 9.9 \\
Food for the family & 144 & 3.84 & $(1.18)$ & 15.2 & 10.9 \\
Financial assistance & 136 & 3.82 & $(1.44)$ & 14.4 & 0.9 \\
Social interaction & 127 & 3.60 & $(1.41)$ & 13.4 & 0.0 \\
Support HIV/AIDS patients & 125 & 3.48 & $(1.66)$ & 13.2 & \\
\hline
\end{tabular}

Note. Ratings on a five-point Likert scale: 5-very high, 4-high, 3-neutral, 2-low, and 1-very low.

All reasons were rated relatively moderately $(M=3.48$ to 4.21$)$. The range of anticipated benefits suggests a multi-dimensional member self-identity. One dimension aligns with reasons related to pursuit of enhanced agricultural production. These production related reasons, namely accessing knowledge and skills, improved seed, and improved animal breeds, received the highest mean ratings (above 4.0). Arguably these reasons were advanced by individuals who had a farmer membership identity. Another dimension aligns with accessing food for the family and financial assistance (mean 3.84 and 3.82, respectively) suggesting an underlying household provider identity. Under this identity a member sees themselves as representing broader, more diffuse domestic interests such as feeding and catering utilities. The third dimension that may be discerned from the data in Table 1 relates to social interaction $(M=$ 3.60) and support to Human Immunodeficiency Virus/Acquired Immune Deficiency Syndrome (HIV/AIDS) affected members $(M=3.48)$. The two items align with the individual's pursuit of private personal gratification. As further illustrated in column 3, there was no outstanding benefit that drew farmers to the groups. Individual reasons were cited by about one in every seven respondents.

A major assumption was that group cohesion would ensue from the three-way relationship between member competence to participate in the activities required of them by the group, member engagement in such activities, and member perception of benefits from such engagement. The study thus sought to describe the status of member participation and perceived benefits accruing from participation in the agricultural production activities promoted by the group (Table 2 and Table 3). 


\section{Table 2}

Members' Competence and Participation in Agricultural Tasks.

\begin{tabular}{lllll}
\hline Agricultural Activities & \multicolumn{2}{l}{$\begin{array}{l}\text { Member } \\
\text { competence }\end{array}$} & \multicolumn{2}{l}{ Participation in tasks } \\
& $\mathrm{M}$ & (SD) & $\mathrm{M}$ & (SD) \\
\cline { 2 - 5 } Goat keeping activities & 4.18 & $(1.81)$ & 1.82 & $(0.81)$ \\
Crop field activities & 3.38 & $(1.20)$ & 1.79 & $(1.92)$ \\
Piggery related activities & 3.35 & $(1.19)$ & 1.98 & $(1.17)$ \\
\hline
\end{tabular}

Note. Ratings on a five-point Likert scale: 5-very high, 4-high, 3-neutral, 2-low, and 1-very low.

A comparison of farmer competence and participation in Table 2 indicates that overall, there was disparity between the self-efficacy and participation/involvement. The 3.35 to 4.18 mean ratings for self-efficacy versus 1.79 to 1.98 for participation indicate an inability or failure to translate above average levels of self-efficacy into corresponding engagement in relevant group tasks. This may be reflective of a perceived mismatch between individual effort and personal rewards. This undercurrent is somewhat borne out by the ordering of perceived benefits accruing from member participation (Table 3).

\section{Table 3}

Perceived Benefits

\begin{tabular}{llll}
\hline Perceived Benefits & $\mathrm{N}$ & \multicolumn{2}{c}{ Rating of perceived benefit } \\
& & $\mathrm{M}$ & $(\mathrm{SD})$ \\
\hline Enhanced group performance & 161 & 4.51 & $(0.82)$ \\
Beneficial to other members & 156 & 4.51 & $(2.53)$ \\
$\begin{array}{l}\text { Beneficial to the group } \\
\text { Improved group maintenance }\end{array}$ & 167 & 4.43 & $(2.31)$ \\
$\begin{array}{l}\text { activities } \\
\text { Enhanced level of personal }\end{array}$ & 175 & 4.40 & $(0.53)$ \\
motivation & 164 & 4.38 & $(0.63)$ \\
$\begin{array}{l}\text { Enhanced attachment to the group } \\
\text { Benefits from others' participation }\end{array}$ & 159 & & \\
\hline
\end{tabular}

Note. Ratings on a five-point Likert scale: 5-very high, 4-high, 3-neutral, 2-low, and 1-very low.

All the top four benefits go toward the group while the remaining lower benefits go toward the individual. This observation may be insightful in two important ways. Olomola (2002) argued participation by individual members in group activities often is influenced by mode of group formation. He associated low participation with what Forsyth (2006) describes as groups concocted through external influence as opposed to those founded by members on their own initiative. Turner and Stets (2006), for their part, emphasized that individuals tend to assess the rewards using a calculus involving balancing their own personal investments against 
investments of other group members toward generating the stock of benefits as well as the equity with which rewards accrue to the contributing members.

A frequently assumed facilitator of group cohesion is the perceived quality of group governance and administrative structures as summarized in Table 4.

\section{Table 4}

Group members' assessment of governance and administrative structures

\begin{tabular}{llll}
\hline Equity Dimension & $\mathrm{N}$ & $\mathrm{M}$ & (SD) \\
\hline Communication within the group & 170 & 4.36 & $(1.09)$ \\
Distribution of leadership positions & 167 & 4.30 & $(0.84)$ \\
Feedback to members about group & 161 & 3.60 & $(0.61)$ \\
performance & & & \\
Conflict resolution & 120 & 2.95 & $(0.75)$ \\
Participation in decision making & 175 & 2.20 & $(0.81)$ \\
\hline
\end{tabular}

Note. Ratings on a five-point Likert scale: 5-very high, 4-high, 3-neutral, 2-low, and 1-very low.

Table 4 indicates different mechanisms established by the group for purposes of moving information up and down the group's governance structures were rated relatively highly $(M=$ 3.60 to 4.36). The high ratings for upward communication from individual members to the group and downward communication point to the groups' sensitivity to ensuring that individuals or teams charged with performing tasks for or on behalf of the group have sufficient information about the groups' dynamics to be attracted to them. This attraction to the group, the results suggest, is reinforced by the perception of equitable distribution of leadership positions that allows the members a sense of access to the groups' resources. The above attraction apparently was undermined by the lower rating for implementation of conflict resolution processes $(M=2.95)$; and availability of opportunities to participate in decision making $(M=2.20)$.

The study also examined membership turnover and group performance for the period 2004 to 2007. The results are summarized in Table 5. Group member's rating of both recruitment of new members $(M=2.64)$ and membership attrition through voluntary departures $(M=2.61)$ farmer groups was moderate. These ratings correspond well with the relatively high sense of belonging to farmer groups $(M=3.96)$. This sense of belonging to the groups could be explained by the selective recruitment of group members by influential group members, most of whom were composed of family members and close friends to group founders. The flip side might be that departures were also partial to those who felt their conflicts with the group had not been addressed fairly and/or that their interests had not been adequately addressed due to insufficient participation in their groups' decision making. In either scenario influential and/or founder group members with very close attraction to each other come to enjoy a special social status and may form a clique whose interests may not necessarily reflect those of the broader membership. 


\section{Table 5}

Membership turnover and effect (2004 -2009)

\begin{tabular}{llllll}
\hline & & \multicolumn{2}{c}{ Group turnover } & Percentage & \\
\cline { 3 - 6 } Turnover & $\mathrm{N}$ & $\mathrm{M}$ & (SD) & High & Very High \\
\hline Joined group & 145 & 2.64 & $(1.10)$ & 27.6 & 25.5 \\
Left group & 155 & 2.61 & $(1.00)$ & 22.6 & 1.9 \\
Pride in belonging & 170 & 3.96 & $(1.09)$ & 23.5 & 43.5 \\
\hline
\end{tabular}

Note. Ratings on a five-point Likert scale: 5-very high, 4-high, 3-neutral, 2-low, and 1-very low.

Table 5 shows that there was high commitment of group members to participation in group activities $(M=4.25)$. The rating of the frequency of group members' participation in group activities ( $M=2.06$ ) was, on the other hand, comparatively low. Read against the rating of adequacy of mobilized resources, and timely attainment of planned targets was quite high $(M=$ 3.03 to 3.53), this gap between commitment to and frequency of participation in activities may point to a lack of consensus on whether production activities should be centralized to the group or decentralized to sites managed by individual members. Moderate ratings were registered for importance of production outputs ( $M=3.01$ to 3.54 ) attained by groups. Taken together the above findings are consistent with Dimock and Devine (1994) and Forsyth (2006) who assert that members tend to be more committed to a group's activities when the efforts and energy invested in activities yield satisfactory output.

\section{Identification of Factors (Dimensions) Influencing Group Cohesion}

Factor analysis was conducted to extract a correlation coefficient matrix of items that are correlated with group cohesion. Factor extraction with rotation resulted in the 37 individual items being reduced to 7 factors/dimensions. The 7 factors accounted for $73.3 \%$ of the total variance. The rotated component matrix was extracted and items with factor loadings less than 0.4 were excluded. Items with factor loadings of $\geq^{ \pm} .4$ that loaded onto the same factor were identified and a common theme was developed to name the respective factor/dimension. Furthermore, correlation coefficient analysis was used to determine the relationship between the various factors (Table 6).

The factors/dimensions were used to create summated Likert type summated scale values Table 7). Group cohesion was defined by frequency at which members joined and left the group. Individual member's objectives were represented by individual member's reporting joining groups to attain knowledge and skills, improved seed for planting, improved animal breeds, food for the family, financial needs, social interaction, and support for HIV/AIDS patients.

Perceptions regarding participation culture were operationalized by farmers reporting interest to work others, attaining personal benefits, interest in seeing all the members benefit, comfort working together, frequency of disagreeing with other members, sense of belonging to a group, attaining benefits without support of the group, and member's influence in decision making. 
Power distance was represented by rating the extent of group member's influence in making major group decisions including frequency and venue of meetings, savings and credit schemes, enterprise to invest in and storage of produce. Group participation in activities was represented by group members regularly participate in group activities and member's commitment to group activities.

Group rewards was defined by farmers' perceptions regarding six items which included satisfaction with the actual group outputs, you have benefited from other group members, your participation benefited other members, the group in general benefited from you, your participation in activities will continue in this group, and you are be proud of belonging to this group. Structure of tasks was defined by farmers' perceptions for three items which included level of involvement in tasks, level of competence and level of influence in group activities. Perceived equity was defined by farmers' perceptions for five items which included criteria used in allocating tasks, distribution of rewards to other group members, the rewards you are given in your group, the way you as an individual are treated in the group, and the way other members of your group are treated. 


\section{Table 6}

Correlation Coefficient of the Factors

\begin{tabular}{|c|c|c|c|c|c|c|c|c|}
\hline Factor & Equity & $\begin{array}{l}\text { Structure } \\
\text { of Task }\end{array}$ & $\begin{array}{l}\text { Group } \\
\text { rewards }\end{array}$ & $\begin{array}{l}\text { Power } \\
\text { distance }\end{array}$ & $\begin{array}{l}\text { Member } \\
\text { participant }\end{array}$ & $\begin{array}{l}\text { Individual } \\
\text { objective }\end{array}$ & $\begin{array}{l}\text { Participant } \\
\text { culture }\end{array}$ & $\begin{array}{l}\text { Group } \\
\text { cohesion }\end{array}$ \\
\hline Equity & 1 & & & & & & & \\
\hline $\begin{array}{l}\text { Structure } \\
\text { of Task }\end{array}$ & $\begin{array}{l}.73^{* *} \\
(P<.001 \\
n=118)\end{array}$ & 1 & & & & & & \\
\hline $\begin{array}{l}\text { Group } \\
\text { rewards }\end{array}$ & $\begin{array}{l}.65^{* *} \\
(P<.001 \\
n=153)\end{array}$ & $\begin{array}{l}.66^{* *} \\
(P<.001 \\
n=118)\end{array}$ & 1 & & & & & \\
\hline $\begin{array}{l}\text { Power } \\
\text { distance }\end{array}$ & $\begin{array}{l}.79^{* *} \\
(P<.001 \\
n=162)\end{array}$ & $\begin{array}{l}.76^{* *} \\
(P<.001 \\
n=118)\end{array}$ & $\begin{array}{l}.66^{* *} \\
(P<.001 \\
n=153)\end{array}$ & 1 & & & & \\
\hline $\begin{array}{l}\text { Member } \\
\text { participant }\end{array}$ & $\begin{array}{l}.83^{* *} \\
(\mathrm{P}<.001 \\
\mathrm{n}=162)\end{array}$ & $\begin{array}{l}.87^{* *} \\
(P<.001 \\
n=118)\end{array}$ & $\begin{array}{l}.75^{* *} \\
(P<.001 \\
n=153)\end{array}$ & $\begin{array}{l}.91^{* *} \\
(P<.001 \\
n=177)\end{array}$ & 1 & & & \\
\hline $\begin{array}{l}\text { Individual } \\
\text { objectives }\end{array}$ & $\begin{array}{l}.91^{* *} \\
(P<.001 \\
n=157)\end{array}$ & $\begin{array}{l}.86^{* *} \\
(P<.001 \\
n=118)\end{array}$ & $\begin{array}{l}.71^{* *} \\
(P<.001 \\
n=153)\end{array}$ & $\begin{array}{l}.77^{* *} \\
(P<.001 \\
n=157)\end{array}$ & $\begin{array}{l}.84^{* *} \\
(P<.001 \\
n=157)\end{array}$ & 1 & & \\
\hline $\begin{array}{l}\text { Participant } \\
\text { culture }\end{array}$ & $\begin{array}{l}.65^{* *} \\
(P<.001 \\
n=162)\end{array}$ & $\begin{array}{l}.80^{* *} \\
(P<.001 \\
n=118)\end{array}$ & $\begin{array}{l}.59^{* *} \\
(P<.001 \\
n=153)\end{array}$ & $\begin{array}{l}.90^{* *} \\
(P<.001 \\
n=172)\end{array}$ & $\begin{array}{l}.87^{* *} \\
(P<.001 \\
n=172)\end{array}$ & $\begin{array}{l}60^{* *} \\
(P<.001 \\
n=157)\end{array}$ & 1 & \\
\hline $\begin{array}{l}\text { Group } \\
\text { cohesion }\end{array}$ & $\begin{array}{l}.83^{* *} \\
(P<.001 \\
n=148)\end{array}$ & $\begin{array}{l}.79^{* *} \\
(P<.001 \\
n=118)\end{array}$ & $\begin{array}{l}.68^{* *} \\
(P<.001 \\
n=148)\end{array}$ & $\begin{array}{l}.83^{* *} \\
(P<.001 \\
n=148)\end{array}$ & $\begin{array}{l}.88^{* *} \\
(P<.001 \\
n=148)\end{array}$ & $\begin{array}{l}.86^{* *} \\
(P<.001 \\
n=148)\end{array}$ & $\begin{array}{l}.79^{* *} \\
(P<.001 \\
n=148)\end{array}$ & 1 \\
\hline
\end{tabular}

$* *$ Correlation is significant at the 0.01 level (2-tailed).

Table 6 indicates that there are statistically significant bivariate relationships between perceived equity $(r=.836, p<.001)$, structure of tasks $(r=.792, p<.001)$, group rewards $(r=.683$, $p<.001)$, power distance $(r=.838, p<.001)$, member participation $(r=.881, p<.001)$, individual member objectives $(r=.868, p<.001)$ and participation culture $(r=-.792, p<.001)$ and group cohesion. This implies that the higher the perceptions regarding the structure of tasks performed by group members, individual member objectives of joining farmer groups, individual member's participation in group activities, the greater is the perceived cohesion within farmer groups and vice versa. Conversely, there was a negative correlation $(r=-.792 ; p$ $\leq .001$ ) between participation culture and perceived group cohesion.

Table 7 summarizes the descriptive statistics for each of the factors/dimensions included in the regression analysis. 


\section{Table 7}

Descriptive statistics for factors/dimensions

\begin{tabular}{llll}
\hline Regression Analysis Factors & $\mathrm{N}$ & $\mathrm{M}$ & (SD) \\
\hline Members' individual objectives & 135 & 3.86 & $(1.38)$ \\
Participation culture & 160 & 3.77 & $(1.54)$ \\
Power distance & 145 & 3.58 & $(1.15)$ \\
Group participation & 118 & 1.86 & $(1.30)$ \\
Group rewards & 118 & 4.42 & $(1.36)$ \\
Structure of tasks & 118 & 3.64 & $(1.40)$ \\
Perceived equity & 159 & 3.48 & $(0.82)$ \\
Group cohesion & 157 & 3.07 & $(1.06)$
\end{tabular}

Note. Ratings on a five-point Likert scale: 5-very high, 4-high, 3-neutral, 2-low, and 1-very low.

Approximately $75 \%(\mathrm{~N}=135)$ indicated they had met their objectives of joining farmers groups, $89 \%(N=160)$ had high collectivist participation culture, $81 \%(N=145)$ experienced high-power distance, had low $(M=1.86)$ participation in group activities, attained very high group rewards $(M=4.41)$, were moderately involved in the structure of tasks $(M=3.64)$ and $87 \%(N=157)$ experienced moderate group cohesion $(M=3.07)$.

Multiple regression was utilized to examine the relative influence of each dimension on perceived group cohesion while simultaneously controlling for the influence of the other dimensions (Table 8). The adjusted $R^{2}$ of 0.842 produced by the regression model $(p<.001)$ indicates that the model explains $84.2 \%$ of the observed variation in group cohesion.

\section{Table 8}

Group Cohesion Regressed on Seven Dimensions

\begin{tabular}{|c|c|c|c|c|c|}
\hline \multirow[b]{2}{*}{ Model ${ }^{\mathrm{a}}$} & \multicolumn{2}{|c|}{$\begin{array}{l}\text { Unstandardized } \\
\text { Coefficients }\end{array}$} & $\begin{array}{l}\text { Standardized } \\
\text { Coefficients }\end{array}$ & \multirow[b]{2}{*}{$t$} & \multirow[b]{2}{*}{$p$} \\
\hline & $B$ & $\begin{array}{l}\text { Std. } \\
\text { Error }\end{array}$ & $\beta$ & & \\
\hline (Constant) & 6.670 & .976 & & 6.833 & $<0.001$ \\
\hline Individual objectives & -0.368 & 0.107 & -0.485 & -3.443 & $<0.001$ \\
\hline Participation culture & -0.006 & 0.166 & -0.003 & -0.039 & 0.969 \\
\hline Power distance & 0.230 & 0.164 & 0.108 & 1.403 & 0.163 \\
\hline Group participation & 0.169 & 0.150 & 0.114 & 1.127 & 0.262 \\
\hline Group rewards & -0.310 & 0.085 & -0.187 & -3.657 & $<0.001$ \\
\hline Structure of tasks & -0.751 & 0.103 & -0.691 & -7.309 & $<0.001$ \\
\hline Perceived equity & 0.190 & 0.091 & 0.204 & 2.092 & 0.039 \\
\hline
\end{tabular}

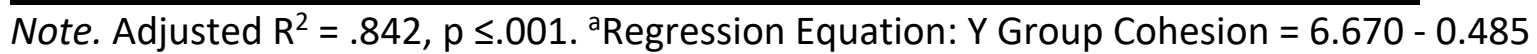

(individual objectives) - 0.187 (group rewards) - 0.691 (structure of tasks) +0.204 (equity) 
The regression results reveal that the nature of individual members' objectives $(\beta=-0.485, p<$ $0.001)$, satisfactoriness of group rewards $(\beta=-0.187, p<0.001)$, and suitability of task $(\beta=-$ $0.691, p<0.001$ ) had negative, statistically significant relationships with group cohesion. In contrast, there was a positive $(\beta=.204, p=.039)$, statistically significant relationship between perceived equity of group processes and group cohesion. Examination of the beta values indicates the dimension labeled structure of tasks had the greatest influence on group cohesion followed by the dimension labeled members' individual objectives. The beta values also reveal the dimension labeled perceived equity and the dimension labeled group rewards had similar, although relatively smaller influence on group cohesion in contrast with structure of tasks and members' individual objectives.

\section{Conclusions, Discussion, and Recommendations}

The new theoretical model that was generated from the findings of regression analysis found significant factors that curtailed and enhanced the cohesion of farmer groups. Group rewards, individual member's objectives, and structure of the tasks the groups engaged in curtailed (negatively influenced) group cohesion. This misalignment has strong implications for group cohesion in both the short and medium term. It is instructive that prevailing levels of group cohesion may have largely been a product of pre-group interaction which influenced recruitment criteria and the subsequent inter-member attraction. Additionally, given that several of the factors that influence group cohesion tended to emanate from the community, it is important for agencies involved in farmer institutional development to deliberately map out the community for important backward and forward linkages to any group operations. It is sufficient to note that the institutional development of farmer groups supported by NAADS pay less attention to group cohesion and more attention to development of skills and competencies for production agriculture. Effective social organization of groups for collective active that is key in groups tends to precede skill and competence development of group members, lest the groups develop cliques, factions which undermine group cohesion before the group disintegrates completely. This could explain the high rate of disintegration and collapse of farmer groups supported by NAADS.

It is also noteworthy that members continued to rationalize their membership, in the face of unmet personal objectives, by deflecting performance failure onto the unfavorable external environment. An extension of this logic is that the groups were formed primarily to take advantage of the opportunities offered by the NAADS environment. Essentially, the members saw themselves as being in contract with the NAADS rather than their own groups. Given that groups supervene on the activities of the constituent individuals; it is difficult to see how group cohesion could be sustained or even enhanced if it is pegged on factors that had little to do with the group's ability to deliver on its contract with members.

The inverse relationship between group cohesion and type/nature of personal objectives is counter intuitive. In this study, one might have expected the largely unmet individual members' objectives to have led to reduced group cohesion. One possible explanation for the observed relationship may be that the reported cohesion has more to do with attraction between 
members and less to do with the de-personalized, attraction to the group (Hogg, 2001). Where this holds, the balance between personal and social attraction tends to be a product of pregroup experiences rather than affiliation to the group engendered by in-group experiences (Forsyth, 2006).

A plausible explanation for the negative relationship between cohesion and extent the group reward system was perceived as satisfactory is that the reward system was rated high because of a perceived cognitive dissonance between members' self-concept as rational individuals and the fact that the system had not sufficiently rewarded them in terms of their initial expected objectives on joining the group. According to cognitive dissonance theory (Greenwald \& Ronis, 1978; Zanna \& Cooper, 1974), members who find themselves in a dissonance situation would be motivated to reduce this uncomfortable tension by rationalizing their behavior. In the circumstances, the group members would justify reward system failure by deflecting the attribution of any injustices to factors beyond the group such as supply of production agriculture inputs by the NAADS program. By extension, inadequate farm inputs would render group activities redundant consequently pushing members to retreat towards their personal farm activities.

Regarding task structure, the tasks that members apparently considered in their evaluation of group effectiveness were of kind that require all group members to participate towards achieving goal. Failure to perform such tasks can be expected to translate into a low perceived collective efficacy (Forsyth, 2006). Based on this logic, the more conjunctive the tasks are perceived to be, the less collectively efficacious members should be expected to feel and hence the less cohesive groups would be likely to be.

The positive correlation between members' participation in group tasks and group cohesion implies that individuals can still jointly participate in group activities but may not have social attraction and positive attitudes towards one another. The only element bringing the individuals together is the task they intend to accomplish. This explains why sometimes individuals sharing a task seem to be disinterested about another. This finding is consistent with Friedkin (2004) that attitudes of individuals in a group such as their desire or intention to remain or leave a group, their identification with or loyalty to the group among others determine the level of social cohesion. Alternatively, individuals may behave in a way that severs, weakens, maintains, or strengthens their membership and participation in a group. Loyal individuals can perform collectively in a group in which he/she is a member. Collective behavior of individuals in a group is an indication of attachment to one another. Membership turnover rate, absenteeism rate and proportion of members who participate in particular group activities are good indications of social cohesion. Poorly performing groups tend to have a high rate of members leaving the group, and absentee from group activities.

Given that international and local development agencies dispense development interventions to mostly farmer groups to scale out development so that its trickle-down effects are improved, these findings come handy for use by organizations engaged in farmer group institutional development to focus on group cohesion as a fundamental driver to group performance 
resulting to improved livelihood of groups members. Therefore, this study findings could help in reorienting the institutional development programs for farmers groups towards building strong cohesive groups that can within stand individual member attritions to achieve collective actions. This is principally important in improving performance and sustainability of farmer groups as the core medium for agricultural and rural development in developing countries, especially in sub-Saharan Africa, Latin America, and East Asia. It is, therefore, important to conduct research on the mindset change capacity building processes in farmer groups and its influence on groups cohesion

\section{References}

Adong, A., Mwaura, F., \& Okoboi, G. (2012). What determines membership to farmer groups in Uganda? Evidence from the Uganda Census of Agriculture 2008/9. Journal of Sustainable Development, 6(4). https://doi.org/10.5539/jsd.v6n4p37

Bukenya, C. (2010). Meeting farmer demand? An assessment of extension reform in Uganda. [Doctoral dissertation, Wageningen University]. Wageningen University and Research. https://library.wur.nl/WebQuery/wurpubs/fulltext/15663.

Cropanzano, R., \& Mitchell, M. S. (2005). Social exchange theory: An interdisciplinary review. Journal of Management, 31(6), 874-900. https://doi.org/10.1177/0149206305279602

Dimock, H. G., \& Devine, I. (1994). Making workgroups effective (3rd ed). Captus Press Inc.

Forsyth, D. R. (2006). Group dynamics (4th ed.). Thomson Wadsworth.

Greenwald, A. G., \& Ronis, D. L. (1978). Twenty years of cognitive dissonance: Case study of evolution of a theory. Psychological Review, 85(1), 53-57.

https://doi.org/10.1037/0033-295X.85.1.53

Hogg, M. A. (2001). A social identity theory of leadership. Personality and Social Psychology Review, 5(3), 184-200. https://doi.org/10.1207/S15327957PSPR0503 1

Lin, Z., Yang, H., Arya, B., Huang, Z., \& Li, D. (2005). Structural versus individual perspectives on the dynamics of group performance: Theoretical exploration and empirical investigation. Journal of Management, 31(3), 354-380. https://doi.org/10.1177/0149206304272150

Mangheni, M.N. (2007). Experiences, innovations and issues in agricultural extension in Uganda: Lessons and prospects. Fountain Publishers.

Ministry of Agriculture Animal Industry and Fisheries. (2010). Agriculture for food and income security: Development strategy and investment plan (DSIP), 2010/11-2014-15. MAAIF. http://extwprlegs1.fao.org/docs/pdf/uga152492.pdf 
Olomola, A. S. (2002). Social capital, microfinance group performance and poverty implications in Nigeria. Nigeria Institute of Social and Economic Resources (NISER). http://citeseerx.ist.psu.edu/viewdoc/download?doi=10.1.1.567.6492\&rep=rep1\&type= pdf

Pigg, K. (1999). Community leadership and community theory: A practical synthesis. Community Development Society Journal, 30(2), 196-212. https://doi.org/10.1080/15575339909489721

Salifu, A., Francesconi, G. N., \& Kolavalli, S. (2010). A review of collective action in rural Ghana (discussion paper 00998). International Food Policy Research Institute, https://www.researchgate.net/profile/Gian Francesconi/publication/46442079 A Revi ew_of_Collective_Action in Rural_Ghana/links/55f933c508aeafc8ac202714/A-Reviewof-Collective-Action-in-Rural-Ghana.pdf

Stolte, J. F., Fine, G. A., \& Cook, K. S. (2001). Sociological miniaturism: Seeing the big through the small in social psychology. Annual Review of Sociology, 27, 387-413. https://doi.org/10.1146/annurev.soc.27.1.387

Turner, J. H., \& Stets, J. E. (2006). Sociological theories of human emotions. Journal of Annual Sociology Review, 32, 25-52. https://doi.org/10.1146/annurev.soc.32.061604.123130

Wilkinson, K. (1991). The community in rural America. Greenwood Press.

Zanna, M., \& Cooper, J. (1974). Dissonance and the pill: An attribution approach to studying the arousal properties of dissonance. Journal of Personality and Social Psychology, 29(5), 703-709. https://doi.org/10.1037/h0036651

(C) 2021 by authors. This article is an open access article distributed under the terms and conditions of the Creative Commons Attribution license (http://creativecommons.org/licenses/by/4.0/). 